\title{
Programs, Proofs, Processes
}

\section{Fernando Ferreira • Benedikt Löwe • Elvira Mayordomo}

The seven papers in this special issue constitute a post-conference publication of the meeting CiE 2010: Programs, Proofs, Processes, held at Universidade dos Açores, Ponta Delgada, Portugal, between June 30 and July 4, 2010. CiE 2010 was the sixth in the series of conferences organized by the Association for Computability in Europe.

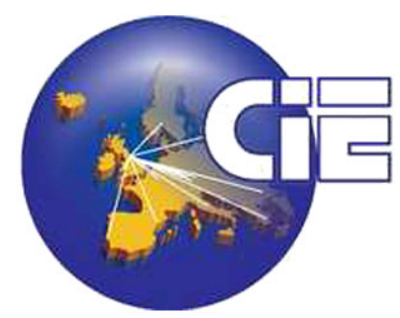

\section{F. Ferreira}

Departamento de Matemática, Faculdade de Ciências, Universidade de Lisboa, Campo Grande, 1749-016 Lisboa, Portugal

e-mail: fjferreira@fc.ul.pt

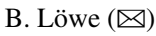

Institute for Logic, Language and Computation, Universiteit van Amsterdam, Postbus 94242, 1090 GE Amsterdam, The Netherlands

e-mail: bloewe@science.uva.nl

\section{B. Löwe}

Department Mathematik, Universität Hamburg, Bundesstrasse 55, 20146 Hamburg, Germany

E. Mayordomo

Departamento de Informática e Ingeniería de Sistemas, Instituto de Investigación en Ingeniería de Aragón (I3A), Universidad de Zaragoza, 50015 Zaragoza, Spain

e-mail: elvira@unizar.es 
The main aim of the association is to promote the development, particularly in Europe, of computability-related science, ranging over mathematics, computer science, and applications in various natural and engineering sciences such as physics and biology. Its aims include the promotion of the study of philosophy and history of computing as it relates to questions of computability.

The theme of CiE 2010 was directed at the usual CiE synergy between computer science, mathematics and logic. The conference addressed not only the more established lines of research of computability and complexity theory and the interplay between proofs and computation, but also novel views that rely on physical and biological processes and models to find new ways of tackling computations and improving their efficiency.

As is usual in computer science, CiE 2010 had a regular pre-proceedings volume published in the Lecture Notes in Computer Science:

Fernando Ferreira, Benedikt Löwe, Elvira Mayordomo and Luís Mendes Gomes (eds.), Programs, Proofs, Processes, Sixth Conference on Computability in Europe, CiE 2010, Ponta Delgada, Azores, Portugal, June 30-July 4, 2010, Proceedings, Ponta Delgada 2010 [Lecture Notes in Computer Science 6158].

As a follow-up to the conference, the organizers of $\mathrm{CiE} 2010$ have also prepared post-conference publications. Three special issues of journals are being edited with journal versions of talks and presentations at CiE 2010. Our publications policy does not allow double publication of the same research content: in order to get accepted for a post-proceedings special issue, a journal version of a talk must exhibit unpublished research content beyond the content printed in the LNCS volume.

This special issue of the journal Theory of Computing Systems is one of the postconference publications. The papers published were submitted by invitation, and the special issue underwent a thorough and strict refereeing process. This was the work of many referees who put in a lot of effort to judge the quality of the special issue. After CiE 2010, we invited ten authors to submit a journal version of their paper to this special issue; in the end, we accepted the seven papers that the reader can find in this volume.

The paper by Guillaume Blin, Romeo Rizzi and Stéphane Vialette represents the special session on Biological Computing (organized by Shankara Krishna and Paola Bonizzoni) and the papers by Eric Allender and Rahul Santhanam represent the session on Computational Complexity (organized by Alan Selman and Luís Antunes) at $\mathrm{CiE}$ 2010. The remaining four papers are full versions of contributed talks. All of the papers in this issue are outgrowths of talks presented at $\mathrm{CiE} 2010$ with a short version published in the mentioned LNCS pre-proceedings volume.

We would like to thank all our referees for their help in producing this special issue, including the members of the CiE 2010 Programme Committee. We are delighted to acknowledge and thank the following for their essential financial support: Universidade dos Açores, Direcção Regional da Ciência, Tecnologia e Comunicações, Associação para a Mobilidade Antero de Quental, Fundação para a Ciência e a Tecnologia, Direcção Regional do Turismo, Elsevier B.V., The Elsevier Foundation, SQIGInstituto de Telecomunicações, Centro de Matemática Aplicada e Tecnologias de In- 
formação, Centro de Matemática e Aplicações Fundamentais, and Association for Symbolic Logic.

For the most current information about the conference series CiE-CS, we refer the reader to our webpage http://www.illc.uva.nl/CiE/. 